\title{
Effect of Ergonomic and Workstyle Risk Factors on Work Related Musculoskeletal Disorders among IT Professionals in India
}

\author{
Deepak Sharan*, Ajeesh PS \\ RECOUP Neuromusculoskeletal Rehabilitation Centre,Bangalore, India.
}

\begin{abstract}
Workstyle' can be described as a mechanism by which ergonomic and psychosocial risk factors interact to affect the development, exacerbation and/or maintenance of upper limb pain and functional limitations. Workstyle is associated with the increase in the work demand. In today's life use of computer in the workplace is very common and it causes to increase the work demand among the workers who are working with computer. As work demand increase, according to the characteristic of workstyle, risk of the development of musculoskeletal disorders also increased. This study aimed at to findout the association between ergonomics risk factors, workstyle and WRMSD. Two hundred IT professionals participated in this study. Result revealed that most prevalenet body regions were lower back (20\%), Upper back (16\%) and shoulder (14\%). Study result says that there is a positive association between workstyle score with musculoskeletal pain $(\mathrm{r}=0.85)$. Also it revealed that posture and regional pain is associated $(\mathrm{r}=0.62)$, per day use of computer and musculoskeletal pain $(\mathrm{r}=0.46)$, micro breaks and pain $(\mathrm{r}=0.87)$ and productivity and the pain $(r=0.95)$. This study further validates these observations and extends support for the assessment of working postures and workstyle behaviors during the design of WMSD treatment.
\end{abstract}

Keywords: workstation information, working posture information, workstyle questionnaire

\section{Introduction}

'Workstyle' is proposed as a mechanism by which ergonomic and psychosocial risk factors interact to affect the development, exacerbation and/or maintenance of upper limb pain and functional limitations [6,9]. Use of computer substantially increased in working populations throughout the world as well as in India. $64 \%$ of Indian IT professionals reported symptoms of pain and discomfort in a recent study [19]. There are several risk factors associated with the development of workrelated musculoskeletal disorders among the workers who use computer extensively at their workplace. All the risk factors can be divided into two major categories [25]. One is occupational and other in non-occupational/personal. Among the occupational repetition, force, awkward/static postures, duration of exposure and vibration are major risk factors. Workstyle is characterized as an individual's response to increased work demands [6].
If there is an increased demand then that affect ${ }^{*}$ physiological and psychological factors which may interact with physical and psychosocial factors at workplace and enhance the relative risk of the development of musculoskeletal disorders. Psychosocial factor is one of the major risk factor that affects musculoskeletal discomfort and studies have shown that improvement of psychosocial risk factors along with physical risk factor is beneficial for the musculoskeletal health [4]. In a cross-sectional study, work style was identified as a possible risk factor for neck and upper extremity symptoms related to office and computer work [6]. Some recent longitudinal studies have supported this finding showing an increased risk of neck and upper extremity symptoms develop among subjects using an unfavorable work style $[6,13]$. Moreover, work style has shown to be related to an adverse health outcome with respect to frequency, intensity and duration of pain, functional limitations and upper extremity symptoms among 
symptomatic office/computer workers [6,20]. Furthermore, that work style has a predictive value for the same variables [10]. There are studies that have contradictory results. Such study revealed that psychosocial factors at the workplace have no association with musculoskeletal discomfort $[2,16]$.

Keeping above in mind it is expected that workers involved in IT profession may have high prevalence of work related musculoskeletal disorders and that may be associated with workstyle and other ergonomics risk factor. The aim of this study was to identify Ergonomic and Workstyle related risk factors that may be associated with the onset or exacerbation of WMSD in Indian IT professionals.

\section{Method}

The data presented in this study was extracted from various IT professionals who were a part of Ergonomic workplace evaluation organized by their company. The assessment consists of five sections that include various factors that may directly or indirectly affect WRMSD while working with computer. Some sections were self-reported checklists that were filled by the employees and some sections were filled by the trained Ergonomists and Physiotherapists of RECOUP. The sections consisted of Demographics (age, gender etc.), workstation information, working posture information (i.e., head and neck in line with torso, forearm, wrist and hand in line), perceived pain and discomfort, and workstyle questionnaire addressing psychosocial factors [6]. Workstyle questionnaire was developed by Feuerstein[7]. This form consists of total 32 items related explaining workstyle at the workplace. Statistical analyses were conducted using the SPSS 17.0 package with a significance level set at $\mathrm{p}<0.05$ for all tests.

\section{Result}

Two hundred participants' data was extracted from the database. The average age of participants was 27.4 \pm 5.2 years. Descriptive analysis of the demographic data indicated that the majority $(69 \%)$ of respondents were males (Table 1).
Table 1.

Demographic data of the participants

\begin{tabular}{ll}
\hline Category & Percentage (\%) \\
\hline Gender & 69 \\
\hline Male & 31 \\
\hline Female & \\
\hline Duration of computer use per day & 1 \\
\hline$<4$ hrs. & 9 \\
\hline 4 - 6 hrs. & 46 \\
\hline 7 -9 hrs. & 45 \\
\hline$>9$ hrs. & 16 \\
\hline Technology used & 69 \\
\hline Desktop & 15 \\
\hline Laptop & \\
\hline Both & \\
\hline
\end{tabular}

$69 \%$ of participants used laptop at work. $45 \%$ of participants used computer for more than 9 hours per day. $68 \%$ of participants reported pain and discomfort during or shortly after they finish work on the computer. Regional pain distribution and prevalence is presented in Figure 1.

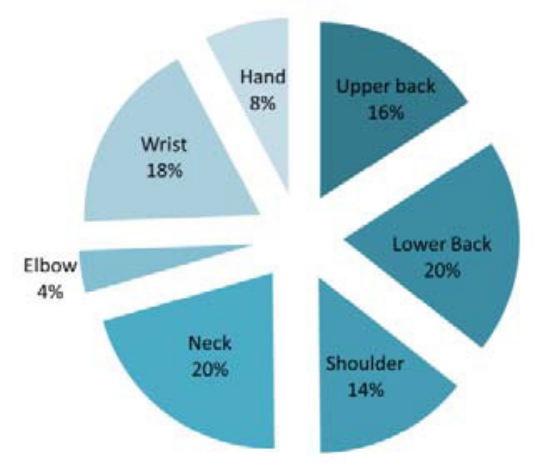

Figure 1. Prevalence of musculoskeletal pain / discomfort

Lower back and neck pain were more prevalent followed by wrist, upper back and shoulder pain. Working postures are represented in Figure 2. 


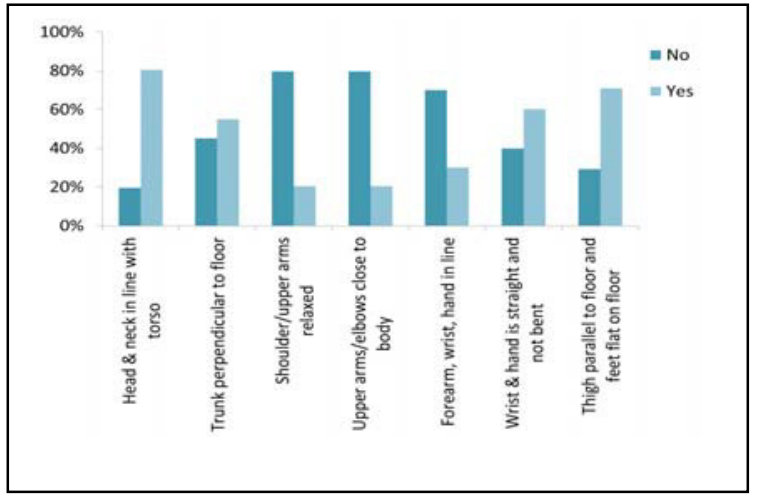

Figure $\cdot$ Different working postures during working with the computer

The Figure 2. revealed that $80 \%$ of participants worked with their upper arm and shoulders raised and away from the body. The short form workstyle questionnaire score analysis indicated $26 \%$ of overall participants were at a high risk (score $\geq 28$ ) of adverse workstyle.

\subsection{Correlation}

Correlation coefficient analyses indicated a significant correlation between workstyle score and musculoskeletal pain $(\mathrm{r}=0.85, \mathrm{p}=0.001)$, posture and regional pain $(\mathrm{r}=0.62, \mathrm{p}=0.005)$, daily computer usage and musculoskeletal pain $(\mathrm{r}=0.46, \mathrm{p}=0.004)$, micro break and pain $(\mathrm{r}=0.87, \mathrm{p}=0.001)$, and between productivity and pain $(\mathrm{r}=0.95, \mathrm{p}=0.001)$.

\section{Discussion}

Studies in literature suggested that intervention in workstyle behavior among computer workers is effective in improvement in some element of workstyle [1] . Recent study revealed a relationship between WRULD complaints and an extreme dedication to one's job, while work style had an intermediate effect [22]. Study findings indicated that social reactivity, lack of breaks, and deadlines/pressure subscales of the workstyle questionnaire were significant predictors of pain. This finding is consistent with previous studies where high job demands, time pressure, high workload, and lack of social support from colleagues and superiors were suggested as risk factors for development of musculoskeletal disorders [2, 5,8,12,14].Psychosocial factors refer to perceptions of the work environment by an individual that can result in stress and strain leading to musculoskeletal symptoms [11]. These factors have been related to negative emotions (e.g. worry, fear) and psychosomatic reactions (e.g. sleep deprivation, tiredness) [24]. Existing evidence suggests a direct influence of psychosocial factors on musculoskeletal pain through physiological changes in the body such as increased blood pressure, increased muscle tension, altered postures, and increased physiological stress response $[3,15,17,24]$.In the present study a significant correlations were observed between Ergonomic risk factors, psychosocial risk factors and musculoskeletal pain symptoms. These findings are in accordance with recent studies evaluating the combined or interactive effects of both physical factors and work-related psychosocial factors on WMSDs [13] . Study carried out by Feuerstein et al on the bank workers revealed that ergonomic intervention with or without a two-time job-stress management training decreased pain and functional disabilities in bank workers with work-related upper extremity musculoskeletal complaints[6]. This result also indicated the importance of a workplace component in treatment of workrelated musculoskeletal disorders. As the present study revealed that there is a positive relation between workstyle score and the prevalence of musculoskeletal pain, it is expected that if any intervention programme implanted which has an effect on the workstyle factor, may reduce the risk of the development of workrelated musculoskeletal disorders among the IT professional. A study concluded that only ergonomic intervention is less effective that the intervention which include both ergonomics and job stress management or workstyle management [10] .

The number of studies examining associations between ergonomic risk factors, psychosocial factors and occurrence of musculoskeletal pain in India are relatively small. This study further validates these observations and extends support for the assessment of working postures and workstyle behaviors during the design of WMSD treatment.

\section{References}

[1] Bernaards C., Ariëns G., Simons M., Knol D., Hildebrandt V., Improving Work Style Behavior in Computer Workers with Neck and Upper Limb Symptoms. J Occupational Rehabilitation, 2008, 18, 87-101.

[2] Bhanderi D., Choudhary S.K., Parmar L., Doshi V., Infl uence of Psychosocial Workplace Factors on Occurrence of Musculoskeletal Discomfort in Computer Operators, Indian Journal of Community Medicine, 2007, 32, 225 -226. 
[3] Bongers P.M., de Winter C.R., Kompier M.A.J., Hildebrandt V.H., Psychosocial factors at work and musculoskeletal disease, Scand J Work Environ Health, 1993, 19, 297-312.

[4] Devereux J.J., Buckle P., Ioannis W., Vlachonikolis G., Interactions between physical and psychosocial risk factors at work increase the risk of back disorders: an epidemiological approach, Occup Environ Med, 1999, 56, 343-353.

[5] Eltayeb S., Staal J., Hassan A., de Bie R., Work related risk factors for neck, shoulder and arms complaints: a cohort study among Dutch computer office workers, J Occup Rehabil, 2009, 19, 315-22.

[6] Feuerstein M. and Nicholas R. A., Development of a short form of the Workstyle measure. Occup Med, 2006, 56, 94 99.

[7] Feuerstein M., Nicolas R.A., Huang G.D., Haufler A.J., Pransky G, Robertson M. Work style: development of a measure of response to work in those with upper extremity pain, J Occup Rehabil, 2005, 15, 87-104.

[8] Feuerstein M., Workstyle: definition, empirical support, and implications for prevention, evaluation, and rehabilitation of occupational upper-extremity disorders. In: Moon SD, Sauter SL, eds. Beyond Biomechanics: Psychosocial Aspects of Musculoskeletal Disorders in Office Work. Bristol, PA: Taylor and Francis Ltd, 1996, 177-206.

[9] Feuerstein M., Huang G.D., Pransky G., Workstyle and work-related upper extremity disorders. In: Gatchel R.J., Turk D.C., eds. Psychosocial Factors in Pain. New York: Guilford, 1999, 175-192

[10] Feuerstein M., Nicholas R.A., Huang G.D., Dimberg L., Ali D., Rogers H., Job stress management and ergonomic intervention for work-related upper extremity symptoms, Applied Ergonomics, 2004, 35, 565 - 574.

[11] Hagberg M., Morgenstern H., Kelsh M., Impact of occupations and job tasks on the prevalence of carpal tunnel syndrome. Scand J Work Environ Health, 1992, 18, 33-45.

[12] Hannan L.M., Monteilh C.P., Gerr F., Kleinbaum D.G., Marcus M., Job strain and risk of musculoskeletal symptoms among a prospective cohort of occupational computer users. Scand J Work Environ Health. 2005, 31, 375-86.

[13] Harrington C.B., Siddiqui A., and Feuerstein M., Workstyle As a Predictor of Pain and Restricted Work Associated With Upper Extremity Disorders: A Prospective Study, The Journal of hand surgery, 2009, 34, 724-731.

[14] Hoogendoorn W.E., van Poppel M.N.M., Bongers P.M., Koes B.W., Bouter L.M., Systematic review of psychosocial factors at work and private life as risk factors for back pain, Spine, 2000, 25, 2114-25.

[15] Huang G.D., Feuerstein M., and Sauter S.L., Occupational stress and work-related upper extremity disorders: Concepts and models, American Journal of Industrial Medicine, 2002, 41, 298-314

[16] Linton S.J., Risk factors for neck and back pain in a working population in Sweden, Work Stress, 1990, 4, $41-49$.

[17] Melin B.. Lundberg U., A biopsychosocial approach to workstress and musculoskeletal disorders, Journal of Psychophysiol, 1997, 11, 238-247.

[18] NRC, Musculoskeletal disorders and the workplace: Low back and upper extremities, 2001

[19] Sharan D., Parijat P., Sashidharan P., Ranganathan R., Mohandoss M., and Jose J., Workstyle Risk Factors for Work Related Musculoskeletal Symptoms among Computer Professionals in India, JOR, 2001.

[20] Toomingas A., Theorell T., Michelsen H., and Nordermar R., Associations between self-rated psychosocial work conditions and musculoskeletal symptoms and signs, Scand J Work Environ Health, 1997, 23, 130-139.
[21] van den Heuvel S., Work-related neck and upper limb symptoms [PhD thesis], Amsterdam. Toegepast Natuurwetenschappelijk Onderzoek, 2006

[22] van den Heuvel S.G., van der Beek A.J., Blatter B.M., Bongers P.M., Workstyle and over commitment in relation to neck and upper limb symptoms, Int J Behav Med, 2007, 14, 12-20.

[23] Warren N., Work stress and musculoskeletal disorder etiology: The relative roles of psychosocial and physical risk factors, Work: A Journal of Prevention, Assessment and Rehabilitation, 2001, 17, $221-234$.

[24] Waersted M., Westgaard R., Attention-related muscle activity in different body regions during VDU work with minimal physical activity, Ergonomics, 1996, 39, $661-676$.

[25] WHO. Identification and control of work-related diseases: Report of a WHO expert committee. Albany, NY: Geneva: World Health Organization, 1985 